БОЛЬ В ПЛЕЧЕ, ТОЛЬКО ЛИ ОСТЕОХОНДРОЗ С ТОЧКИ ЗРЕНИЯ ВРАЧА-РЕВМАТОЛГА? (МЕЖДИСЦИПЛИНАРНАЯ ПРОБЛЕМА)

DOI: $\frac{10.31618 / E S U .2413-9335.2019 .1 .67 .338}{\text { Щербаков Григорий Ильич }}$

Кандидат медицинских наук, врач-ревматолог «Медицинская практика», 2. Кемерово, Россия

\title{
SHOULDER PAIN; IS IT ONLY CERVICAL OSTEOCHONDROSIS FROM THE POINT OF VIEW OF THE REVMATOLOGIST? (INTERDISCIPLINARY PROBLEM)
}

\author{
G.I. Shcherbakov \\ Candidate of medical sciences, \\ rheumatologist "Medical practice", \\ Kemerovo, Russia
}

\section{РЕЗЮМЕ}

Адгезивный капсулит называют «замороженным» плечом. Связано это с тем, что патологический процесс поражает плечевой сустав настолько сильно, что становится абсолютно неподвижным. Если вовремя не предпринять меры это может привести к снижению качества жизни пациента, к инвалидности. Согласно литературным данным в группу риска такого заболевания попадают в основном пациенты 40-60 лет женского пола. Адгезивный капсулит плечевого сустава часто развивается на фоне дистрофических и гормональных изменений, происходящих в тканях, после полученных травм или перенесенных инфекций. В итоге в результате повреждения или физиологического изнашивания околосуставной ткани синовиальная жидкость начинает вырабатываться в уменьшенном объеме, что провоцирует воспалительный процесс (синовит), и плечевая капсула утрачивает свою эластичность. Если лечение адгезивного капсулита плечевого сустава начато не вовремя, тогда шансы не велики, двигательная функция сустава будет восстановлена не полностью. Для блокирования воспалительного процесса могут назначаться лекарства группы нестеройдных противоспалительных препаратов, миорелаксантов, приём хондропротекторов. Если же нестероидные средства не дают ожидаемого эффекта, тогда к лечению заболевания подключается внутрисуставное введение глюкортикостероидных препаратов (Дипроспан), введение гиалуроновой кислоты. Только патогенический подход к лечению (нестероидные противоспалительные препараты, миорелаксанты, хондропротекторы, глюкокортикоидные препараты, гиалуроновая кислота) могут значительно улучшить качество жизни пациента.

\section{SUMMARY}

Adhesive capsulitis is called "frozen" shoulder. This is due to the fact that the pathological process affects the shoulder joint so much that it becomes completely stationary. If you do not take measures in time, it can lead to a decrease in the quality of life of the patient, to disability. According to the literature, the risk group of this disease includes mostly patients 40-60 years of female. Adhesive capsulitis of the shoulder joint often develops against the background of dystrophic and hormonal changes occurring in the tissues after injuries or infections. As a result, as a result of damage or physiological wear of the periarticular tissue, synovial fluid begins to be produced in a reduced volume, which provokes an inflammatory process (synovitis), and the shoulder capsule loses its elasticity. If the treatment of adhesive capsulitis of the shoulder joint is not started in time, then the chances are not great, the motor function of the joint will not be fully restored. To block the inflammatory process, drugs of the group of non-steroidal anti-inflammatory drugs, muscle relaxants, chondroprotectors can be prescribed. If non-steroidal drugs do not give the expected effect, then the treatment of the disease is connected to the intra-articular administration of glucorticosteroid drugs (Diprospan), the introduction of hyaluronic acid. Only a pathogenic approach to treatment (no steroidal anti-inflammatory drugs, muscle relaxants, chondroprotectors, glucocorticoid drugs, hyaluronic acid) can significantly improve the quality of life of the patient.

Ключевые слова: адгезивный капсулит, «замороженное» плечо, качество жизни, внутрисуставное введение препаратов.

Key words: adhesive capsulitis, "frozen" shoulder, quality of life, intra-articular administration of drugs.

Адгезивный капсулит - представляет собой диффузное поражение капсулы и синовиальной оболочки плечевого сустава, нередко приводящее длительной инвалидизации пациента [1].

Впервые своеобразный «плечевой» синдром, сопровождающийся болью и значительным ограничением объема движений, но не связанный с поражением собственно плечевого сустава, в 1882 году описал Duplay. Он же ввел в практику термин «плечелопаточный периартрит», который позже стал необоснованно применяться ко всей группе периартикулярных заболеваний области плечевого сустава. В 1932 году Codman предложил для обозначения этого состояния термин «замороженное плечо», который до настоящего времени популярен в англоязычной ортопедической литературе [2,3]. Данное название отражает один из наиболее характерных признаков заболевания - закономерное наступление в течение заболевания периода «скованности» - безболевого 
ограничения движений в плечевом суставе. В отечественной медицине использовались аналогичные термины - «блокированное плечо», плечелопаточный периартрит с ограничением движений в плечевом суставе. В 1945 году Naviesar предложил современное название - «адгезивный капсулит.

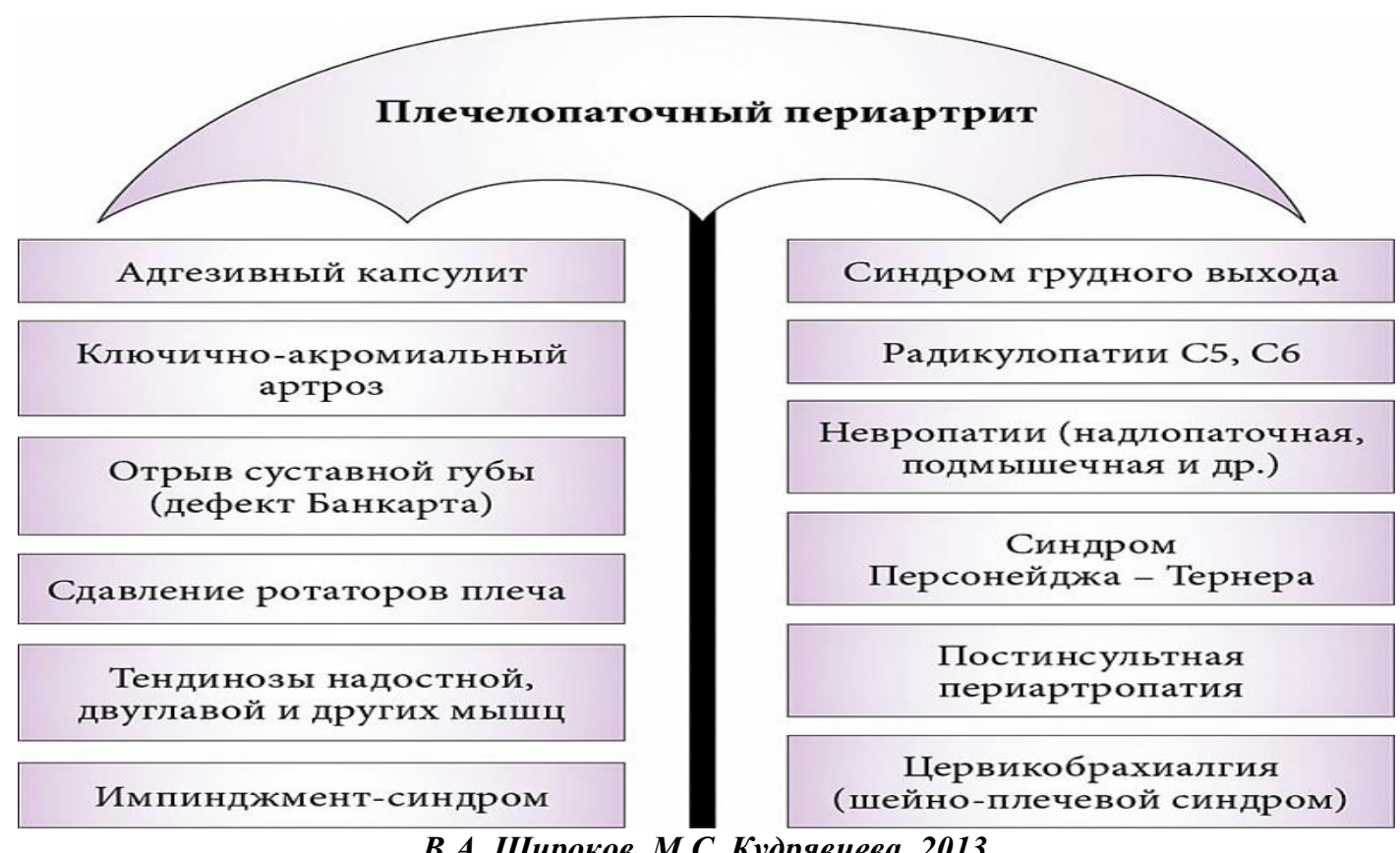

В.А. Широков, М.С. Кудрявцева, 2013

Рис.1. Плечелопаточный синдром - диагноз, для обозначения периартикулярных поражений плечевой области

Адгезивный капсулит встречается с частотой $3-5 \%$ в общей популяции, повышаясь до $20 \%$ у больных сахарным диабетом, и является одним из самых частых заболеваний опорно-двигательного аппарата. Хотя ряд авторов описывают адгезивный капсулит как заболевание, самостоятельно проходящее в течение 1-3 лет, другие исследования указывают, что 20-50\% пациентов испытывают ограничение движений в плече долгое время, в том числе свыше 10 лет. В абсолютном большинстве

Норма

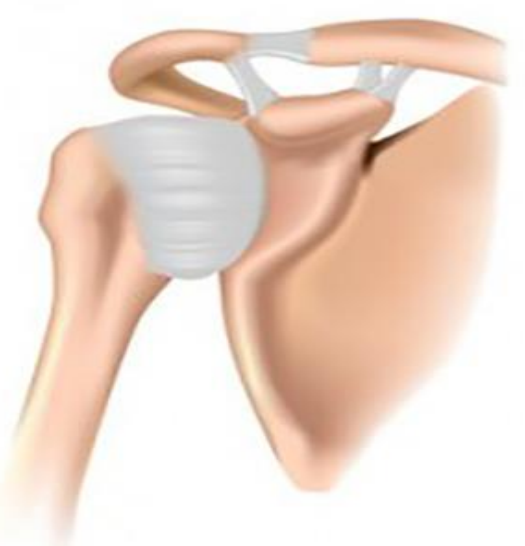

случаев капсулит встречается у лиц в возрасте от 50 до 70 лет. Женщины болеют чаще мужчин (соотношение 3:1-5:1). Доминирующая и недоминирующая конечность поражаются с равной частотой. В 7-10\% случаев на фоне разрешения процесса в одном суставе развивается поражение второго сустава с интервалом

от 6 месяцев до 5 лет. После выздоровления повторные эпизоды капсулита в том же суставе крайне редки [4].

\section{Адгезивный капсулит}

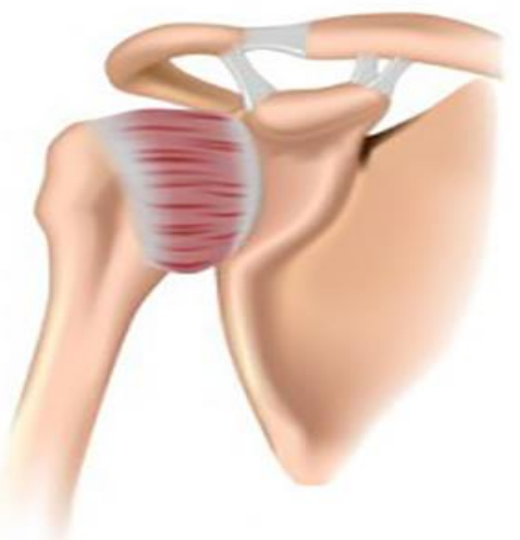

O.C. Страфун, 2017

Рис.2. Изменение капсуль при адгезивном капсулите

Выделяют первичный (идиопатический) и вторичный адгезивный капсулит. Первичный подразделяют на наружный и внутренний.
Наружнный. Связан со сдавлением сухожилий вращательной манжеты, длинной головки бицепса и субакромиальной синовиальной сумки между 
головкой плечевой кости и лежащими над ней жесткими структурами (акромион, акромиальноключичный сустав, клюво-акромиальная связка). Причины: остеофиты в области акромиальноключичного сустава и неправильное сращение проксимальных переломов плечевой кости.

Внутренний. Встречается в основном у спортсменов (броски и другие движения, связанные со значительным отведением плеча). Идет перетирание сухожилия подостной мышцы в зоне его контакта с задним краем суставной впадины в момент, когда рука переводится в положение максимального отведения и наружной ротации.

Для первичного адгезивного капсулита характерно постепенное начало и прогрессирование заболевания без какой-либо определенной причины. Симптомы могут прогрессировать так медленно, что пациент не обращается за медицинской помощью до тех пор, пока ограничение движений в суставе или боль значительно не ограничивают ежедневную активность. В противоположность этому больные со вторичным адгезивным капсулитом обычно сообщают о своих симптомах вскоре после падения или провоцирующей травмы.

Развитие вторичного адгезивного капсулита происходит на фоне уже имеющейся патологии мягких тканей. Характерная причина такого рода изменений - небольшое нарушение стабильности плечевого сустава. Связанный с физической активностью легкий подвывих головки плеча может индуцировать капсулит за счет значительного сужения субакромиального пространства. Фиброз капсулы у больных с синдромом замороженного плеча может вызывать передне-верхнее смещение головки плечевой кости со сгибанием плеча, что также может стать причиной сужения субакромиального пространства и возникновения вторичного адгезивного капсулита[5].

Таким образом, клиническими проявлениями адгезивного капсулита являются: ноющие тупые боли в области плечевого сустава, которые усиливаются при определённых видах движений, как правило, усиление боли происходит в ночное время, в более поздних стадиях появляется слабость и ограничение подвижности сустава. В связи с очевидностью клинической картины заболевания диагностических критериев капсулита не существует. При постановке диагноза используют клинические признаки, данные осмотра пациента, данные рентгенологических и ультразвуковых исследований, компьютерную и магниторезонансную томографию, определение острофазовых показателей (С-реактивного белка, ревматоидного фактора)[6].

Дифференциальную диагностику необходимо проводить с артритом плечевого сустава, нарушением его стабильности, с остеоартритом акромиально-ключичного сустава, переломами плечевой кости и ключицы, с инфекциями, опухолями костей, с невралгическими амиотрофиями, синдромом апертуры грудной клетки, заболеваниями сердца, печени, селезёнки, патологическими изменениями в области диафрагмы.

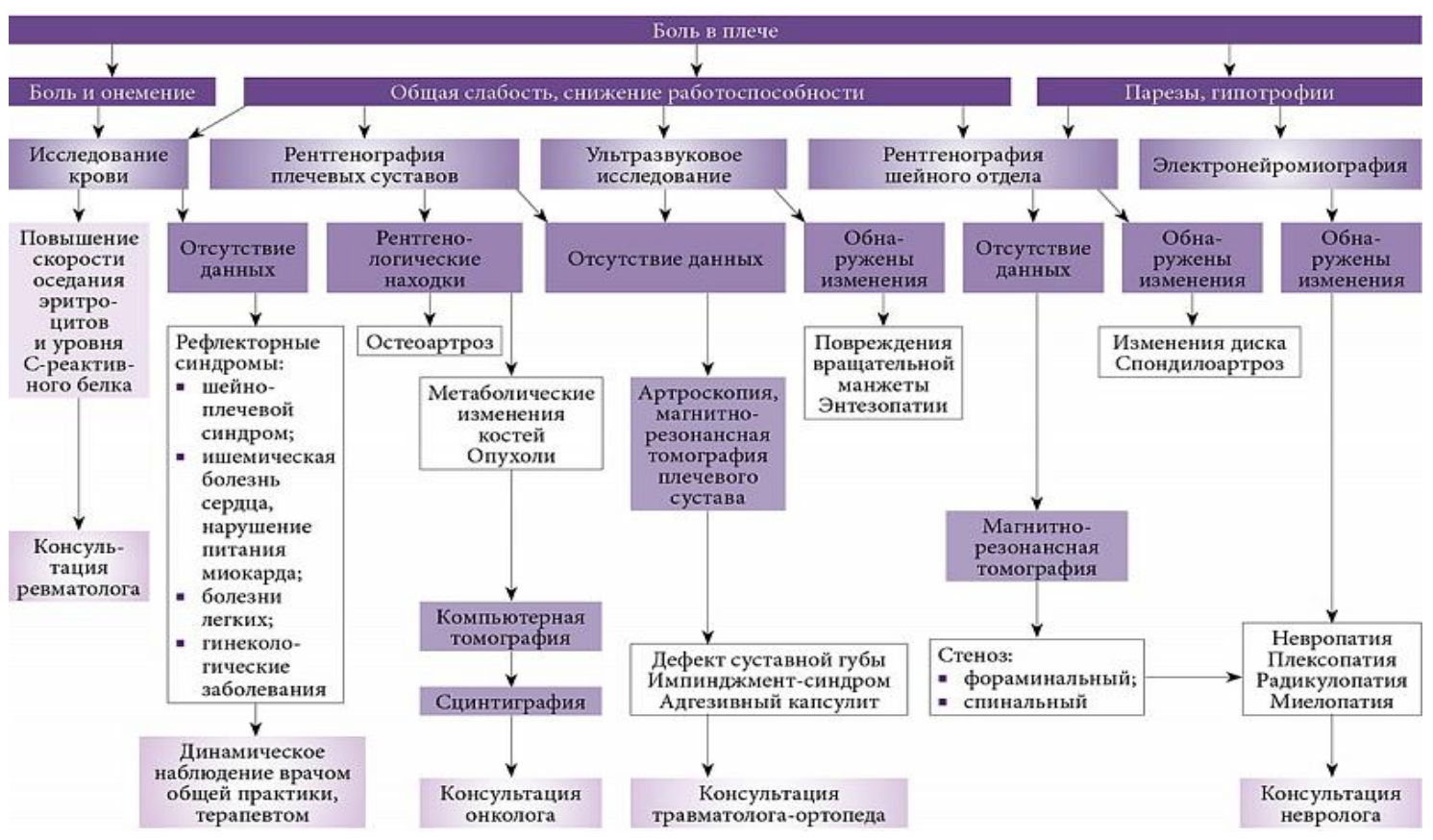

В.А. Широков, М.С. Кудрявцева, 2013

Рис.3. Диагностический алгоритм болевого синдрома плеча

Основной задачей терапии является уменьшение болевого синдрома и улучшение функциональных показателей: мышечной силы и объема движений в плечевом суставе, что обусловливает улучшение качества жизни [7]. 


\section{Терапия боли}

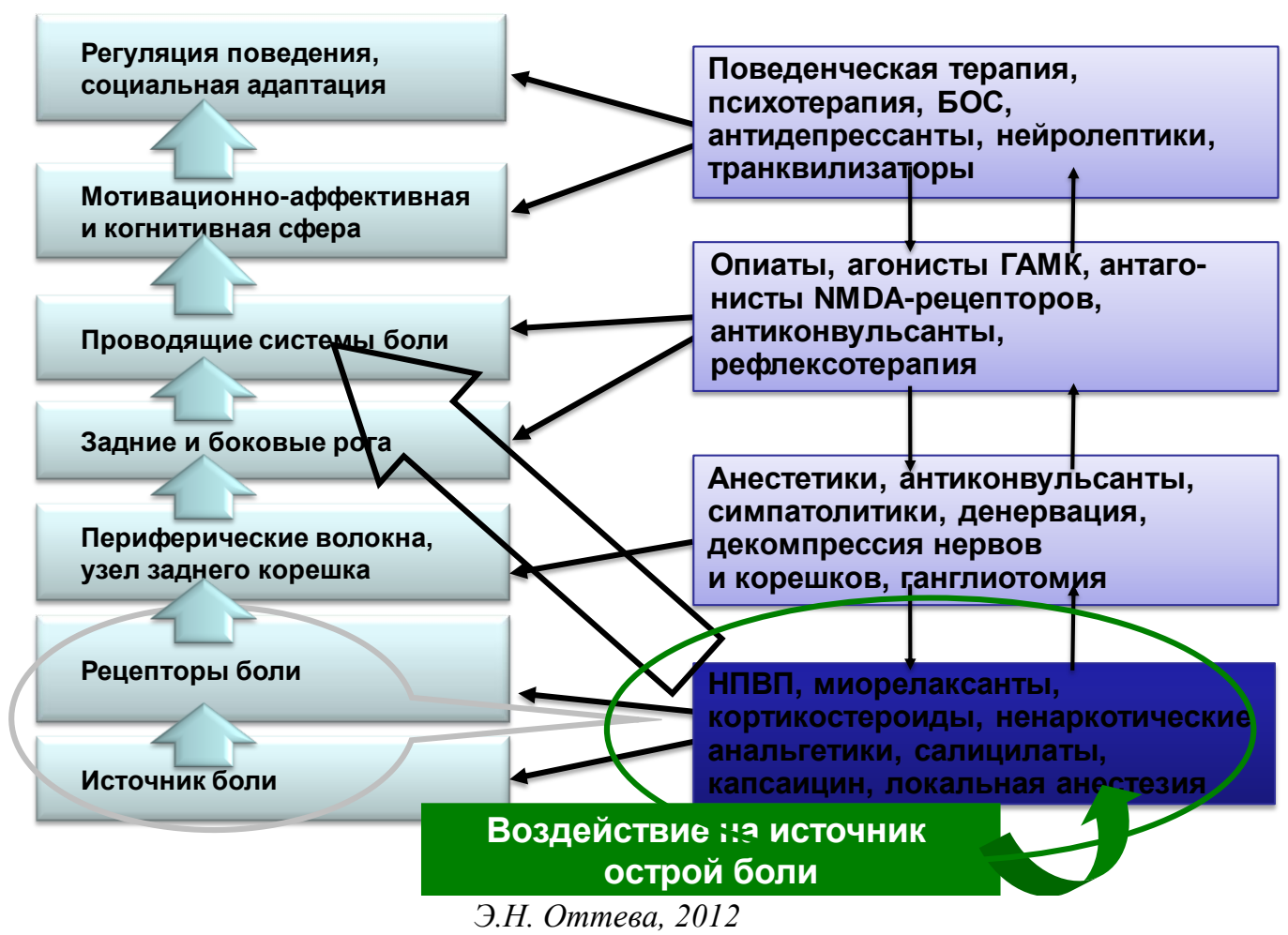

Рис.4. Алгоритм лечения болевого синдрома плеча

Целью исследования являлось оценить эффективность и безопасность лечения комбинации внутрисуставного введения препарата гиалуроната натрия 20 мг $3 /$ мл и внутримышечного введения гликозаминогликан-пептидного комплекса по 1 мл в течение 5-6 недель у пациентов с адгезивным капсулитом.

\section{Материалы и методы исследования}

В исследовании приняли участие 50 женщин с адгезивным капсулитом, диагностированным на основании клинических проявлений, объективного осмотра, ультразвуковым методом исследования аппаратом AcuVista RS880D с высокочастотным датчиком L3-1/7.5МГц с диапазоном глубины сканирования 40-90 мм.

Средний возраст пациентов составил 40,46 $\pm 11,22$ лет, возраст на момент начала заболевания $34,98 \pm 10,96$ лет, период от проявления первых симптомов болезни до установления диагноза $2,32 \pm 2,48$ лет.

Исследование проведено в соответствии с принципами Хельсинкской декларации Всемирной медицинской ассоциации (в редакции 2000г с разъяснениями, данными на генеральной ассамблее ВМА, Токио, 2004), с правилами Качественной Клинической Практики Международной Конференции по Гармонизации (ICH GCP), этическими принципами, изложенными в Директиве Европейского союза 2001/20/ЕС и требованиями национального Российского законодательства. Каждый больной подписал «Информированное согласие» на участие в исследовании.

Статистический анализ данных проводился с использованием пакета прикладных программ Microsoft Office Excel 2003 (лицензионное соглашение 74017-640-0000106-57177) и StatSoftStatistica 6.1 (лицензионное соглашение BXXR006D092218FAN11). Характер распределения данных оценивали с помощью критерия Шапиро-Уилка. В зависимости от вида распределения признака применялись различные алгоритмы статистического анализа. Количественные данные представлены центральными тенденциями и рассеянием: среднее значение (М) и стандартное отклонение (s) признаков, имеющих приближенно нормальное распределение, медиана (Ме) и интерквартильный размах (25-й и 75-й процентили) в случае распределения величин отличного от нормального.

Всем больным, включенным в исследование, был выполнен общий анализ крови, С-реактивный белок (СРБ). Интенсивность боли оценивался по визуально аналоговой шкале (ВАШ).

Длительность исследования - 6 месяцев. Оценка эффективности и безопасности лечения проводилась по состоянию здоровья пациента по ВАШ, оценки эффективности терапии врачом и пациентом, суточной потребности НПВП. Введение гиалуроната натрия 20 мг/мл - 2мл проводилось в субакромиальное пространство однократно под контролем ультразвукового аппарата, внутримышечное введение 
гликозаминогликан-пептидного комплекса составляло 1-й день - 0.3 мл, во 2-й день - 0.5 мл и далее 3 раза в неделю по 1 мл в течение 5-6 недель.

Результаты и обсуждение

Анализируя статистические данные, на фоне проводимой терапии, через месяц отмечено статистически значимое снижение боли в плече по ВАШ 5,0 $(3,00 ; 8,00)$ мм, СОЭ $30(15,0 ; 47,0)$ мм/час, СРБ $6,45(4,20 ; 11,0)$ мг/л. Это подтверждает, что действительно имеется взаимосвязь между интенсивностью боли в плече и признаков воспаления со стороны анализа крови и СРБ. К 3 и 6-му месяцам наблюдения боль не нарастала и составляла по шкале ВАШ 4,5 $(3,00 ; 7,5)$. Кроме снижения боли по ВАШ, наблюдалось снижение СОЭ $15,00(5,00 ; 37,00)$, СРБ 5,20 $(2,40 ; 16,00)$.

В начале исследования все 50 пациентов (100\%) принимали НПВП. В плане безопасности приёма был назначен Мелоксикам внутримышечно по 1,5мл №5 один раз в день с переходом на таблетированную форму в дозе 15 мг в день. Через неделю 12 человек (24\%) полностью отказались от приёма НПВП, через 1 месяц - 26 человек (52\%), к 6-му месяцу - 38 человек (76\%), лишь 12 человек (24\%) продолжали принимать НПВП.

\section{Выводы}

Полученные данные свидетельствуют о хорошем симптоматическом эффекте приёма НПВП, препарата Гиалуром Тендон 1\%-2.0 однократно субакромиальное пространство в комбинации с внутримышечным введением Румалона по схеме в течение 5-6 недель. На фоне терапии у пациентов статистически значимо отмечалось снижение боли, потребность в НПВП.

Внутрисуставная терапия в виде инъекций в настоящее время занимает прочное место в артрологии. Не являясь основным методом лечения, позволяет подавить воспаление в суставе (купирование болевого синдрома) оптимальным способом. Наиболее часто используемая техника - введение препарата в субакромиальное пространство и является более предпочтительным и более эффективным методом лечения. Внутримышечное введение гликозаминогликан-пептидного комплекса увеличивает биодоступность и долю крупномолекулярных комплексов, что повышает эффективность терапии. За последнее время накоплен достаточный опыт применения инъекционных форм хондропротекторов при остеоартрите и их справедливо считают патогенетически обоснованными средствами базисной терапии остеоартрита. Хондропротекторы, благодаря биологическому сродству с суставным хрящом, легко проникают в него, подавляют активность протеолитических ферментов, стимулируют обмен хрящевой ткани, задерживают развитие дегенеративного процесса.

\section{Декларация о финансовых и других взаимоотношениях}

Исследование не имело спонсорской поддержки. Автор несёт полную ответственность за предоставление окончательной версии рукописи в печать. Материалы статьи ранее не опубликованы и не направлены в настоящее время в другой журнал.

\section{Список литературы}

1.Беленький А. Г. Патология плечевого сустава. Плече-лопаточный периартрит. Прощание с термином: от приблизительности к конкретным нозологическим формам. «Consilium medicum», 2004, т. 6, №2. C. 1511

2. Dias R. et al. Frozen shoulder. BMJ, 2005.331: 1453-56

3.Rizk T.E., Pinals R.S. Frozen shoulder. Seminars Arthritis Rheumatism 1982; 11:440-52.

4.Шамсутдинова Н.Г.Кирилова Э.Р. Адгезивный капсулит плеча. Практическая медицина. 2013. Т. 1. №1-2 (69). С. 138-140.

5.Беленький А. Г. Капсулит («замороженное плечо») / А.Г. Беленький // РМЖ. - 2006. - Т. 14, №21. C. 1511-1515.

6.Никифоров А.С., Мендель О.И., Плече-лопаточный болевой синдром: современные подходы к диагностике и лечению. РМЖ. -2006, Т. 14, №8. - С.621-6.

7.Широков В.А., Кудрявцева М.С. Болевые синдромы плечевого пояса: диагностика и лечение. Эффективная фармакотерапия, 2013, 2: 46-55 